\title{
Applications of polymer blends in drug delivery
}

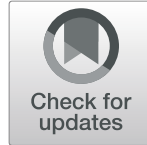

Nasser N. Nyamweya(D)

\begin{abstract}
Background: Polymers are essential components of many drug delivery systems and biomedical products. Despite the utility of many currently available polymers, there exists a demand for materials with improved characteristics and functionality. Due to the extensive safety testing required for new excipient approval, the introduction and use of new polymers is considerably limited. The blending of currently approved polymers provides a valuable solution by which the limitations of individual polymers can be addressed.

Main body: Polymer blends combine two or more polymers resulting in improved, augmented, or customized properties and functionality which can result in significant advantages in drug delivery applications. This review discusses the rationale for the use of polymer blends and blend polymer-polymer interactions. It provides examples of their use in commercially marketed products and drug delivery systems. Examples of polymer blends in amorphous solid dispersions and biodegradable systems are also discussed. A classification scheme for polymer blends based on the level of material processing and interaction is presented.

Conclusion: The use of polymer blends represents a valuable and under-utilized resource in addressing a diverse range of drug delivery challenges. It is anticipated that new drug molecule development challenges such as bioavailability enhancement and the demand for enabling excipients will lead to increased applications of polymer blends in pharmaceutical products.
\end{abstract}

Keywords: Polymer blends, Drug delivery, Dosage forms, Solid dispersions, Bioavailability enhancement

\section{Background}

Polymers are widely used in the formulation of pharmaceutical and healthcare products. Applications include controlling drug release, providing site specific delivery of active pharmaceutical ingredients (APIs) and improving drug stability. Polymers are commonly used in almost all major dosage forms including tablets, films, capsules, semi-solids, suspensions, gels, and transdermal patches as well as in specialized delivery systems such as long-acting injections and biodegradable implants.

There are a variety of polymers currently available with unique properties which have been used in marketed drug and healthcare products. Due to this precedent of use, these polymers may be used in the development of new pharmaceutical products, provided

Correspondence: nasser04@yahoo.com

Pharma Manufacturing Solutions, P.O. Box 21297-00505, Nairobi, Kenya that the amounts used are within the limits for which safety has been established. Despite the availability of these polymers, there is a demand for new and improved materials. While synthesis of new polymers to obtain desired functionalities is possible, the extensive safety testing requirements for new materials are often a limiting barrier to their use in new drug products. Considering the time and resources required to obtain regulatory approval when a new excipient is to be utilized, polymer blends present an attractive alternative means by which to address various formulation and drug delivery challenges.

The goal of blending polymers from a functionality standpoint is to improve, customize, or maximize material performance [1]. Table 1 lists applications of polymer blends in pharmaceutical dosage forms. Various mechanisms of drug release from polymer-based dosage forms 
Table 1 Pharmaceutical applications of polymer blends

\begin{tabular}{ll}
\hline Dosage forms* & Applications \\
\hline Tablets & Modulation of drug release profiles \\
Hard and soft capsules & Capsule shell formation, enteric protection \\
Film coatings & $\begin{array}{l}\text { Plasticization, modulation of mechanical } \\
\text { properties, adhesion, vapor permeability } \\
\text { and drug release rates }\end{array}$ \\
Oral films & $\begin{array}{l}\text { Plasticization, modulation of mechanical } \\
\text { properties. Preventing settling of dispersed }\end{array}$ \\
phases; modulating tear resistance \\
Liquids, emulsions, and suspensions & $\begin{array}{l}\text { Rheological adjustment, suspension stabilization } \\
\text { Topical semi-solids and transdermal patches }\end{array}$ \\
Rheological modification, modulation of diffusion, \\
swelling, dissolution/erosion and drug release rates \\
Solid dispersions & $\begin{array}{l}\text { Rheological/mechanical properties modification, } \\
\text { modulation of bioadhesion and drug release rates }\end{array}$ \\
& $\begin{array}{l}\text { Modulation of degradation, drug release rate and } \\
\text { mechanical properties }\end{array}$ \\
& $\begin{array}{l}\text { Drug solubilization, dissolution enhancement, } \\
\text { stabilzation of solid state forms, crystallization inhibition, } \\
\text { modulation of super-saturation and precipitation inhibition }\end{array}$
\end{tabular}

*Specific examples for various dosage forms are listed in Tables 2, 3, 4, and 5

are possible depending on the type of delivery system (Fig. 1). The scientific literature on the application of polymer blends in pharmaceutical products, excipients, and drug delivery systems has mostly focused on specific properties or applications of polymer blends such as miscibility [35, 36], film coating $[37,38]$, orally disintegrating films [39], matrix tablets [40-42], solid dispersions [43-45], biodegradable systems [46, 47], transdermal drug delivery [48], environmentally responsive systems $[49,50]$, and modifying or improving the performance of natural polymers [51-55]. Polymer blends have been used in recently emerging pharmaceutical processing techniques such as 3D printing [56-58] and electrospinning [59-61]. These techniques have also been used to prepare polymer blends for use in tissue engineering and wound dressings [62, 63]. Although most studies reported in the literature have focused on binary polymer blends, there has been some work performed on blends with more than two polymers such as ternary polyvinyl alcohol/poly(vinylpyrrolidone)/chitosan blends [64].

Despite the potential advantages of polymer blends, there is an absence of comprehensive reviews on their use and application in marketed products. Furthermore, the currently available literature on polymer blends in pharmaceuticals is very product specific and is highly fractured across many scientific journals, publications and patents. This paper therefore reviews the applications of polymer blends in excipients and drug delivery systems across a broad range of different dosage forms with an emphasis on commercialized products and technologies. Applications of polymer blends in drug solubility enhancement are also addressed.

\section{Main text \\ Polymer blend interactions}

Noncovalent polymer-polymer interactions may range from van der Waals forces in physical mixtures to stronger intermolecular interactions such as hydrogen bonding, ionic interactions, and hydrophobic interactions that may occur during processing. Many experimental techniques are available for the characterization of polymer blends depending on the state of the material being studied [65]. Widely used methods include molecular weight characterization, spectroscopy, light and $\mathrm{x}$-ray scattering, diffraction, microscopy, imaging techniques, thermal analysis, rheology, and mechanical testing in conjunction with evaluation of long term product stability.

Key factors influencing polymer-polymer interactions are shown in Fig. 2. These factors include the characteristics of the polymers, blend composition (i.e., polymer ratio), the type of manufacturing process, processing conditions, solvent, and other ingredients in the formulation. For example, varying the polymer chemistry (poly(lactide-co-glycolide) with various lactide and glycolide ratios), anti-solvent and process temperature was observed to influence the degree of interaction and phase separation in blends of these biodegradable polymers with chitin [66].

Polymer blend interactions can also be influenced by the addition of other components. For example, the addition of sodium carboxymethyl cellulose ( $\mathrm{NaCMC})$ was found to facilitate miscibility in polyvinyl alcohol (PVA) and polyethylene oxide (PEO) solutions which exhibited phase separation in the absence of the ionic polymer [67]. The authors ascribed the miscibility 


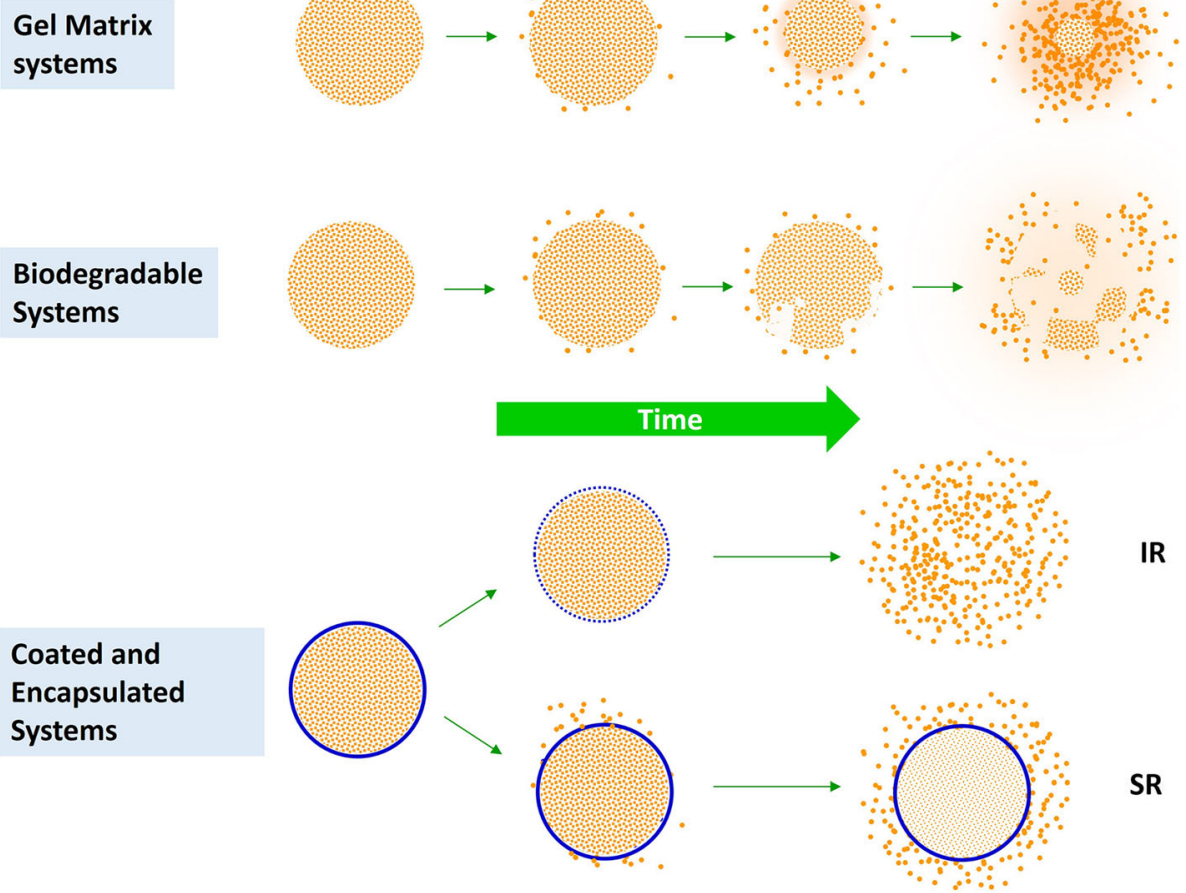

Fig. 1 Mechanism of drug release from the polymer-based drug delivery systems discussed in this paper. IR, immediate release; SR, sustained release. Spheres represent drug molecules. In the matrix and biodegradable systems shown, the polymer is uniformly distributed with the drug. Drug release occurs by diffusion through the matrix and gel erosion (e.g., hypromellose-based tablets) or biodegradation (e.g., poly(lactide-coglycolide)-based systems). In coated or encapsulated systems, a polymer forms a film or shell around drug particles. In coated IR systems, the film dissolves rapidly, while in coated SR systems, drug release occurs gradually by diffusion through an insoluble polymer film

enhancement to the ability of $\mathrm{NaCMC}$ to form hydrogen bonds with both PVA and PEO.

Environmental factors such as temperature and humidity are an important consideration during long-term storage since they may influence drug product stability. Yang et al. reported that a ternary system of amorphous felodipine hot melt extruded with an immiscible Eudragit $^{\ominus} \mathrm{EPO} /$ poly(vinylpyrrolidone-co-vinyl acetate) polymer blend exhibited better stability of the amorphous drug to stress temperature and humidity compared to binary drug-polymer blends [68].

\section{Polymer blend classification}

In polymer chemistry literature, polymer blends are usually described as being miscible (i.e., homogeneous at the molecular level), partially miscible or immiscible [65]. From a pharmaceutical product viewpoint, this review proposes a further classification based on the dimensional scale in which the bulk of the polymer molecules in the blend are processed and interact (Fig. 3 ). The term "bulk" in this context refers to the majority of molecules. For example, in powders, the bulk of the polymer molecules are in the interior of the constituent particles as opposed the surface. The scheme classifies polymer blends as occurring on three levels-particulate, colloidal, and molecular. These levels correspond to the size range of the polymer particles that are used to prepare the blend. Particle size is an important material parameter for pharmaceutical products as it influences several key manufacturing and product performance attributes. These include powder mixing, blend uniformity and solvent interaction rates. Consequently, given the wide variety of polymer blends that have been used in a range of different applications and dosage forms, classification systems which distinguish between blends based on key physical properties are useful in further understanding their characteristics. An additional consideration is whether a polymer blend exhibits long term stability in the sense that it does not undergo physical changes or phase separation during storage. This is especially a concern for (initially miscible) molecular level blends which in the absence of specific intermolecular interactions and a sufficient enthalpy of mixing may undergo phase separation leading to changes in the properties of the blend. Consequently, molecular level blends may require a more detailed investigation of their physical characteristics and microstructure compared to particulate or colloidal level blends. For explanatory purposes, the following discussion will focus on binary 


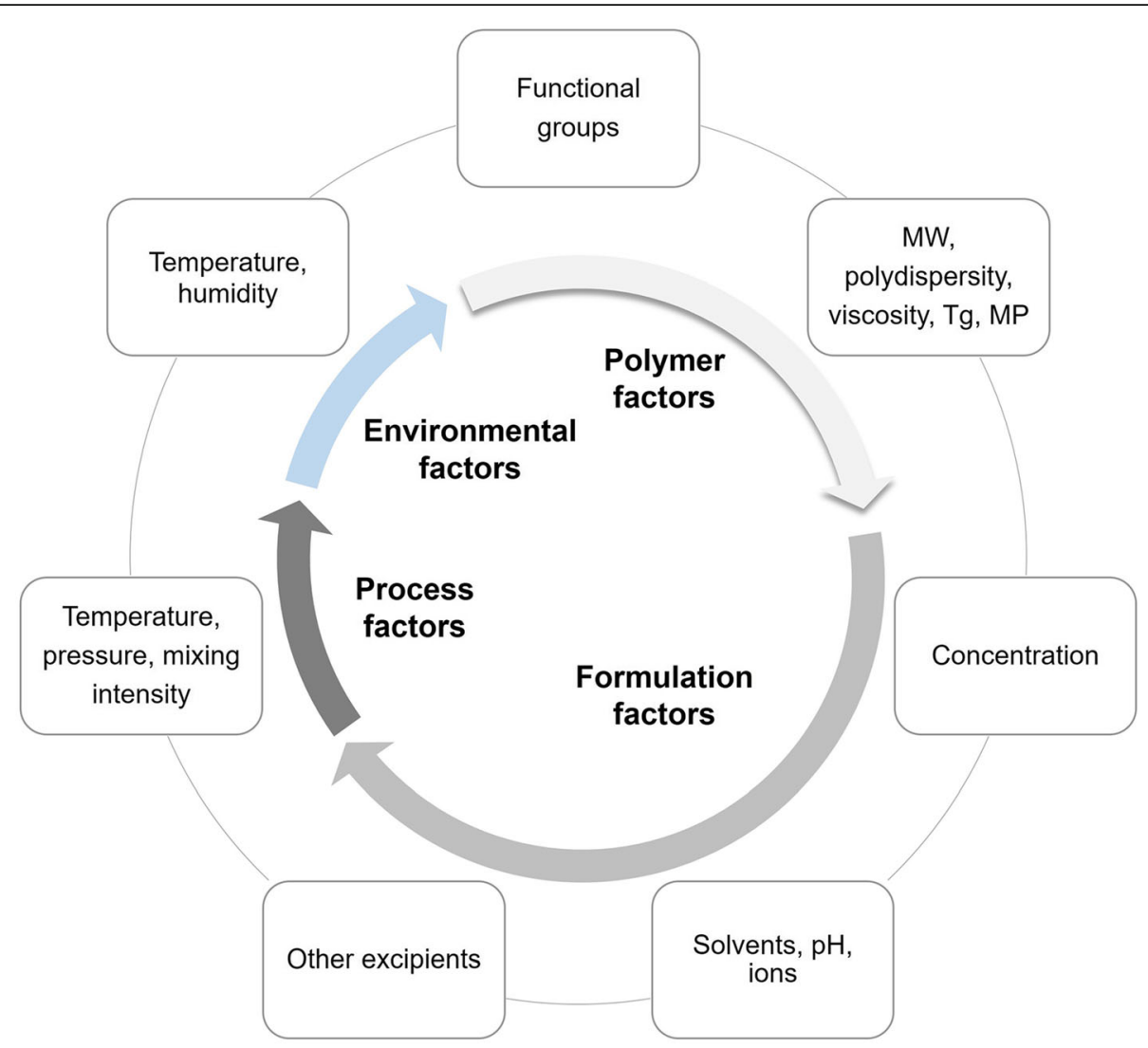

Fig. 2 Factors influencing polymer-polymer interactions. Tg, glass transition temperature (amorphous polymers); MP, melting point (crystalline polymers); MW, molecular weight

blends although the concepts are also applicable to blends of more than two polymers.

\section{Particulate level blends}

Particulate level blends are formed by the mixing of polymers as powders which do not undergo further processing to reduce their initial particle size substantially. Pharmaceutical manufacturing processes such as direct compression, roller compaction, and wet granulation use powders which are generally in the size range of tens to hundreds of microns. The level of interactions between materials processed by these techniques is generally confined to powder surfaces. Therefore, polymer blends used in most conventional tableting operations can be considered to have inter-polymer interactions occurring at a particle level. Additionally, the uniformity of mixing in such polymer blends does not extend beyond individual particles. The addition of water or organic solvents during wet granulation processes may promote a certain degree of localized mixing at particle surfaces or interfaces.

Examples of particulate level blends from commercial products are not readily available as specific particle size information for individual blend excipients that are used is not commonly published. Therefore, the distinction between particulate level and some colloidal level blends may not always be readily determinable. However, in general, most direct compression and granulation processes would be considered to be particulate level blends given the size of their constituent particles. A relevant example from the recent literature describes the use of 90-250 $\mu \mathrm{m}$ particle size range chitosan and xanthan gum blends for use as a direct compression matrix [69]. In this case, the polymer blend is clearly at the particulate level given its particle size range and the use of a direct compression process which does not involve size reduction of the powders.

\section{Colloidal level blends}

In colloidal level blends, at least one of the polymers predominantly exists as aggregates that are near or within the submicron size range. Such systems can be obtained by methods such as communition, mixing of colloids (e.g., latex polymer dispersions), or phase separation (e.g., from solution, dispersions or melt processed polymer blends). Polymeric mixed micelles, which are formed by the assembly of two or more amphiphilic block copolymers $[55,70]$, may also be included in this 


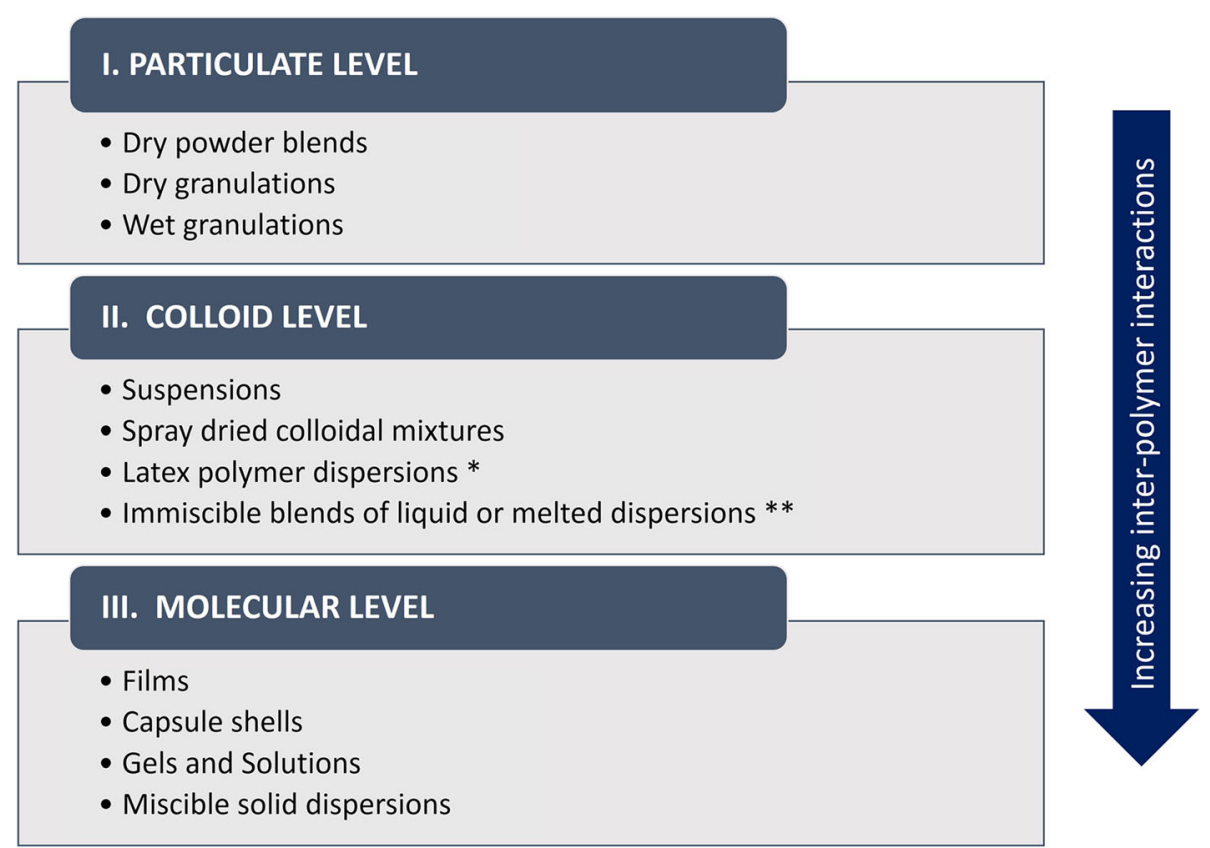

Fig. 3 Polymer blend processing/mixing level classification. Examples reflect the level to which the polymers used have been processed. Single sterisk indicates that depending on process conditions and polymer miscibility, latex dispersions can coalesce and become molecular level blends. Double asterisk indicate that immiscible or partially miscible blends with colloidal size aggregates, which an arise from (i) process conditions not dispersing polymers to the molecular level or (ii) polymers demixing during processing (e.g., two immiscible polymers demixing from a common solvent during drying of a film)

class of polymer blends. The increase in unit surface area relative to that of particulate level blends results in the interfacial region having a greater influence on interpolymer interactions. Surface charge therefore plays an important role in these polymer blends.

For colloidal polymer particles dispersed in liquids, flocculation may occur if the two species have opposite surface charges. In aqueous latex dispersions that are used for film coating, flocculation may also occur upon the addition of water soluble polymers which are sometimes used as pore forming agents [71]. Nonionic water soluble polymers may cause flocculation of polymeric dispersions by bridging flocculation (adsorbed polymers) or depletion flocculation (nonadsorbed polymers) [72, 73].

An example of a commercial product that is a colloidal level blend is Avicel ${ }^{\circ}$ RC 591 (a co-processed microcrystalline cellulose (MCC) and sodium carboxymethyl cellulose $(\mathrm{NaCMC})$ powder) which is discussed further in the section on excipients of this review. The product is manufactured by spray drying an aqueous dispersion of colloidal MCC (water insoluble) and NaCMC (water soluble) [74]. $\mathrm{NaCMC}$, an anionic polymer, adsorbs onto the surface of the colloidal MCC particles [75]. The particle size of this product after dispersion in water is around $90-200 \mathrm{~nm}$ [76], which reflects the starting size of the MCC used to manufacture it. The interaction between the two polymers has been attributed to electrostatic forces and hydrogen bonding [76].

\section{Molecular level blends}

Molecular level blends are formed by processing two polymers in or to a state where they can interact at a molecular level. Processing methods generally involve the use of a common solvent or thermally co-processing the polymers together in molten or above the glass transition temperature (Tg) states. Depending on their thermodynamic compatibility, polymer ratio, and the temperature, the resulting mixture may have one or more detectable phases. Examples of systems containing blends in which polymers can be homogenous at the molecular level include clear films, capsule shells, gels, and solutions. Polymer-polymer miscibility in all proportions has been observed for hypromellose (HPMC) and methylcellulose blend films, with mixing following ideal behavior [36]. In films and capsule shells, polymer miscibility is desirable as it generally results in clear, transparent films (if there are no insoluble or highly crystalline additives). Molecular scale interactions are also important in amorphous solid dispersions so that the drug does not crystallize during the shelf life of the drug product. In solutions, polymer-polymer miscibility reduces the potential for phase separation. 


\section{Excipients}

Polymer blends have been used as excipients for suspending and stabilizing disperse systems. An example is the previously mentioned $\mathrm{MCC}$ and $\mathrm{NaCMC}$ blend. Co-processed $\mathrm{MCC} / \mathrm{NaCMC}$ is available as a powder and has monographs in the USA and European pharmacopoeias. Several types are available from different manufactures with the $\mathrm{NaCMC}$ level ranging from 5 to $22 \%$ [77]. The co-processed product is used to create thixotropic gels that are used to stabilize suspensions, emulsions, and gels. For this reason, MCC/ $\mathrm{NaCMC}$ is used in several marketed nasal spray products including Avamys [78], Beconase [79], and Nasacort Allergy [80].

The viscosity of MCC/NaCMC systems is less affected by temperature changes than that of $\mathrm{NaCMC}$ solutions. The NaCMC component serves as a protective colloid reducing inter-particle interactions that may lead to the aggregation of the MCC particles. NaCMC also facilitates dispersion of the $\mathrm{MCC} / \mathrm{NaCMC}$ powder when it is dispersed in water [81]. The stabilizing properties of $\mathrm{MCC} / \mathrm{NaCMC}$ have been attributed to it forming aqueous dispersions having a three-dimensional network structure [76].

Another excipient based on a polymer blend is Avicel ${ }^{\circ}$ CE 15, a co-processed MCC and guar gum (85:15) powder that is used to provide improved mouth feel in chewable tablets. MCC and guar gum combinations have been studied as fat substitutes due to their favorable sensory characteristics [82]. The product is also claimed to add a creamy mouthfeel while reducing tooth packing and grittiness thereby improving the overall sensory characteristics of chewable tablets $[83,84]$. Avicel $^{\circ} \mathrm{CE}$ 15 is manufactured by co-processing MCC and guar gum into rounded aggregates by spray drying an aqueous mixture of the two components [4]. As in the production process used for $\mathrm{MCC} / \mathrm{NaCMC}$, the manufacturing method for Avicel ${ }^{\circ} \mathrm{CE} 15$ uses colloidal size $\mathrm{MCC}$ as a starting material, which would make it a colloidal level blend. The beneficial organoleptic properties of the Avicel $^{\circ} \mathrm{CE} 15$ product are attributed to the intimate association of the polymers achieved during coprocessing as well as the rounded shape of the aggregates [4].

\section{Tablets}

While tablets are complex mixtures in which nonpolymeric excipients such as sugars and polyols may be more prevalent (on an overall tablet weight basis), there are a number of cases where polymer blends provide unique functionality (Table 2). As for most direct compression and wet granulated based powder mixtures, these products would be classified as particulate level blends with the exception of the previously discussed co-processed Avicel ${ }^{\circ}$ CE 15 excipient.

Polymers have been used extensively in the formulation of sustained (SR) release tablets. SR products are advantageous as they provide a reduction in dosing frequency and better control of the therapeutic window. Matrix tablets based on hydrogel forming polymers are commonly used in this regard. Gel formation creates a diffusion barrier to water and soluble drug substances. Gel erosion also contributes to drug release, especially for poorly soluble actives. HPMC, the most widely used polymer in this field, is available in a range of chemical substitution types and molecular weight grades [85]. Different HPMC molecular weight grades can be blended, thereby providing a convenient approach by which to adjust drug release profiles. Furthermore, it has been observed that such blends can increase the robustness of matrix tablets to hydrodynamic conditions during dissolution [86]. This finding has been attributed to the contribution of the higher molecular weight HPMC grades to forming stronger gels that are more resistant to changes in media agitation speeds.

In addition to viscosity and gel strength, other polymers blended with HPMC may influence matrix hydration, swelling, and erosion rates [86]. An interesting concept has been the addition of other polymers to HPMC matrices to control pH-dependent dissolution profiles of ionizable APIs [87, 88]. In some cases, the use of ionic polymers with HPMC has resulted in $\mathrm{pH}$ independent drug release for weak bases [89] and weak acids [90]. In the latter study, this effect was attributed to the control of microenvironmental $\mathrm{pH}$ by the basic polymer, Eudragit ${ }^{\circledR} \mathrm{E} 100$.

Certain polymer blends can produce synergistic effects in which a combination of two polymers results in a change in a measured property that is greater than

Table 2 Polymer blends in tablet technology platforms and excipients

\begin{tabular}{|c|c|c|c|}
\hline Polymers & Advantage(s) & $\begin{array}{l}\text { Commercial } \\
\text { Product }\end{array}$ & Reference \\
\hline $\begin{array}{l}\text { Polyethylene oxide, } \\
\text { hypromellose }\end{array}$ & $\begin{array}{l}\text { Gastric retention and controlled drug release faciliating upper Gl tract delivery by } \\
\text { controlled swelling and erosion }\end{array}$ & $\begin{array}{l}\text { Acuform } \\
\text { Technology }\end{array}$ & [2] \\
\hline $\begin{array}{l}\text { Xanthan gum, locust bean } \\
\text { gum }\end{array}$ & Sustained release from synergistic polymer interaction & $\begin{array}{l}\text { TIMERx } \\
\text { Technology }\end{array}$ & [3] \\
\hline $\begin{array}{l}\text { Microcrysalline cellulose, } \\
\text { guar gum }\end{array}$ & Improved sensory charcteritics of chewable tablets & Avicel ${ }^{\circledR}$ CE 15 & {$[4]$} \\
\hline
\end{tabular}


would be expected from the sum of the individual components. Synergistic rheological effects have been observed for combinations of $\mathrm{NaCMC}$ (anionic) and HPMC (non-ionic) with the increases in viscosity being attributed to hydrogen bond mediated cross-linking between the carboxylic acid and hydroxyl groups of the polymers [91]. An advantage of such synergistic combinations is that they allow for a reduction in the overall concentrations of the polymers required in the formulation, which is useful when the drug product size or excipient levels must be minimized [2, 91]. Polymer blends have also been used in matrix tablets for the design of specific drug release profiles. Mixing nonionic (HPC or methylcellulose) and anionic ( $\mathrm{NaCMC}$ ) polymers in optimum amounts has been used to obtain zero-order release profiles for two highly soluble drugs (metoprolol tartrate and alprenolol hydrochloride) [40]. This was in contrast to the individual polymers which yielded firstorder or sigmoidal dissolution profiles. The reasons for the observed zero order release profiles of the polymer combinations have not been fully elucidated, but it has been proposed that an interaction between the cationic forms of these APIs and NaCMC may lead to the formation of a complex which is released at a slower rate permitting a modulation of drug release to a constant rate when the appropriate levels of nonionic and anionic polymer are used [92, 93].

TIMERx is a matrix tablet drug delivery technology that was developed based on synergistic interactions between xanthan gum and locust bean gum. When used together, the association between the polymer secondary structures formed in solution enhances gelation and viscosity resulting in a much stronger gel than that of the individual polymers [3]. Modulation of drug release profiles from these matrix tablets can be accomplished by varying factors such as the ratio and concentration of the polymers, as well as the addition of ions and saccharides. Acuform ${ }^{\circ}$ is a gastro-retentive drug delivery technology based on the use of PEO and HPMC [94]. In this regard, the aim of gastric retention is to maintain the drug product in the stomach for an extended duration so as to prolong the time during which APIs with a narrow absorption window can be absorbed. Rapidly swelling systems are one means by which to improve gastric retention as larger dosage forms are emptied from the stomach more slowly. In the Acuform ${ }^{\circ}$ system, PEO is used as a rapidly swelling and SR matrix former. HPMC is described as modulating the rate of PEO swelling and erosion so that a more even and reproducible drug release profile is obtained [2]. The use of HPMC also permits lower levels of PEO to be used, which is important due to the lower daily intake limits for PEO [95].

\section{Film coatings and oral films}

Polymer blends have been used extensively in the film coating of tablets, pellets, and capsules. A second polymer may be used with a primary film former to improve adhesion to the substrate, modify the mechanical properties of the coating, improve moisture protection, or to modulate drug release. Cost reduction may be another reason for combining polymers. A number of commercially marketed film coating systems are based on polymer blends. These include products for both non-functional (immediate release) and functional (controlled release) coatings (Table 3).

Table 3 Polymer blends used in film coatings

\begin{tabular}{|c|c|c|c|}
\hline Polymers & Advantage(s) & $\begin{array}{l}\text { Commercial product/ } \\
\text { application }\end{array}$ & Ref. \\
\hline $\begin{array}{l}\text { Polyvinyl alcohol, polyethylene glycol } \\
\text { (PEG) } 3350\end{array}$ & $\begin{array}{l}\text { PEG } 3350 \text { can be used as a dry powder plasticizer for fully } \\
\text { formulated coating systems }\end{array}$ & Opadry II 85F & {$[5]$} \\
\hline Hypromellose, hydroxypropyl cellulose & Improved adhesion, increased film elasticity & SheffCoat ${ }^{T M} \mathrm{HS}$ & {$[6]$} \\
\hline Hypromellose, polyvinyl alcohol & Improved mositure protection, increased film elasticity & SheffCoat ${ }^{\mathrm{TM}} \mathrm{MP}$ & {$[6]$} \\
\hline Hypromellose, polydextrose or starch & $\begin{array}{l}\text { Cost reduction; shorter ccoating times due to higher spray } \\
\text { solids contents due lower viscosity }\end{array}$ & $\begin{array}{l}\text { SheffCoat }{ }^{T M} \text { D (HPMC/ } \\
\text { polydextrose) } \\
\text { SheffCoat }{ }^{T M} \text { S (HPMC/starch) }\end{array}$ & {$[6]$} \\
\hline P-MAA-EA, P-EA-MMA & $\begin{array}{l}\text { Increased film flexibility, eliminates plasticizer requirments } \\
\text { and facilates the compression of enteric coated particles }\end{array}$ & Eudragit ${ }^{\oplus} \mathrm{FL} 30 \mathrm{D}-55$ & {$[7]$} \\
\hline $\begin{array}{l}\text { P-EA-MMA-TMAEMA }(1: 2: 0.2) \\
\text { P-EA-MMA-TMAEMA }(1: 2: 0.1)\end{array}$ & Modulation of drug release rates & $\begin{array}{l}\text { Eudragit }{ }^{\oplus L} \text { and } R S \\
\text { combinations for sustained } \\
\text { release }\end{array}$ & {$[8]$} \\
\hline $\begin{array}{l}\text { Ethylcellulose, sodium } \\
\text { alginate }\end{array}$ & $\begin{array}{l}\text { Alginate serves as a pH-dependent pore former and provides } \\
\text { enteric functionality, GRAS excipient-based enteric film coating } \\
\text { for nutraceuticals }\end{array}$ & Nutrateric ${ }^{\circledast}$ & {$[9]$} \\
\hline
\end{tabular}

Abbreviations: P-MAA-EA poly(methacrylic acid-co-ethyl acrylate) (1:1), P-EA-MMA poly(ethyl acrylate-co-methyl methacrylate) (2:1), P-EA-MMA poly(ethyl acrylate-comethyl methacrylate), $P$-EA-MMA-TMAEMA poly(ethyl acrylate-co-methyl methacrylate-co-trimethylammonioethyl methacrylate chloride), GRAS generally regarded as safe 
Non-functional coatings are applied for the purpose of esthetic appearance, product identification, improving stability (to moisture and light) and taste-masking. The most commonly used polymers for non-functional coating are low-viscosity HPMCs. When HPMC is used for tablet coating, the addition of plasticizers is required to improve film flexibility. Polyethylene glycol (PEG) is commonly used as a plasticizer for HPMC films. Another mechanical property that can be modified by blending additional polymers with HPMC is film-substrate adhesion. Hydroxypropyl cellulose (HPC) is an example of a polymer which has been blended with HPMC to improve film adhesion. HPC has also been reported to reduce logo bridging and film cracking at the edges when used with HPMC [96]. Additional reasons for using polymeric blends in nonfunctional film coatings are to improve drug stability by reducing water vapor permeability, to reduce the duration of the coating process, and to prepare dry, fully formulating coating systems.

Polymer blends have been used extensively as functional film coatings for controlled release applications [97]. Although functional film coatings may be applied using organic solvent-based solutions, there is a preference for aqueous systems which are latex dispersions [98, 99]. These systems are colloidal dispersions of water insoluble polymers such as polymethacrylates, ethylcellulose, or poly(vinyl acetate). In addition to drug release rate and mechanical properties modulation, polymeric additives may be used to improve the long term dissolution profile stability of controlled release film coatings [100].

An example of the use of a polymer blend to obtain optimized mechanical properties is illustrated in the tableting of enteric coated particles (Fig. 4). In tableting of coated particles, films of the enteric polymer Eudragit ${ }^{\circ}$ L 30D-55 tend to be brittle and fracture during compression. The polymer Eudragit ${ }^{\circ} \mathrm{NE}$ 30D however, while not possessing enteric functionality, is extremely flexible and its films when coated onto particles retain integrity during compression. Mechanically, the percent elongation at break values of Eudragit ${ }^{\circ}$ L 30D-55 and Eudragit $^{\circ}$ NE 30 D films are $14 \%$ and $600 \%$, respectively [8]. A blend of the two polymers can therefore be used to prepare coatings that are flexible enough to withstand compression while maintaining enteric functionality.

Film coatings based on natural or generally regarded as safe (GRAS) materials appeal to nutraceutical and dietary supplement markets. This is because the typical enteric polymers used for pharmaceutical products have daily intake limits. One approach to developing enteric film coatings for nutritional products has been to use GRAS polysaccharides with anionic functional groups. Nutrateric ${ }^{\circ}$ a coating system based on the use of a combination of sodium alginate and ethylcellulose has been developed on this principle $[9,101]$. In this blend, ethylcellulose serves as the primary film former. The alginate polymer provides enteric protection due to $\mathrm{pH}$ dependent ionization of its carboxylic acid groups. At low $\mathrm{pH}$ it is insoluble, while at higher $\mathrm{pH}$, it dissolves

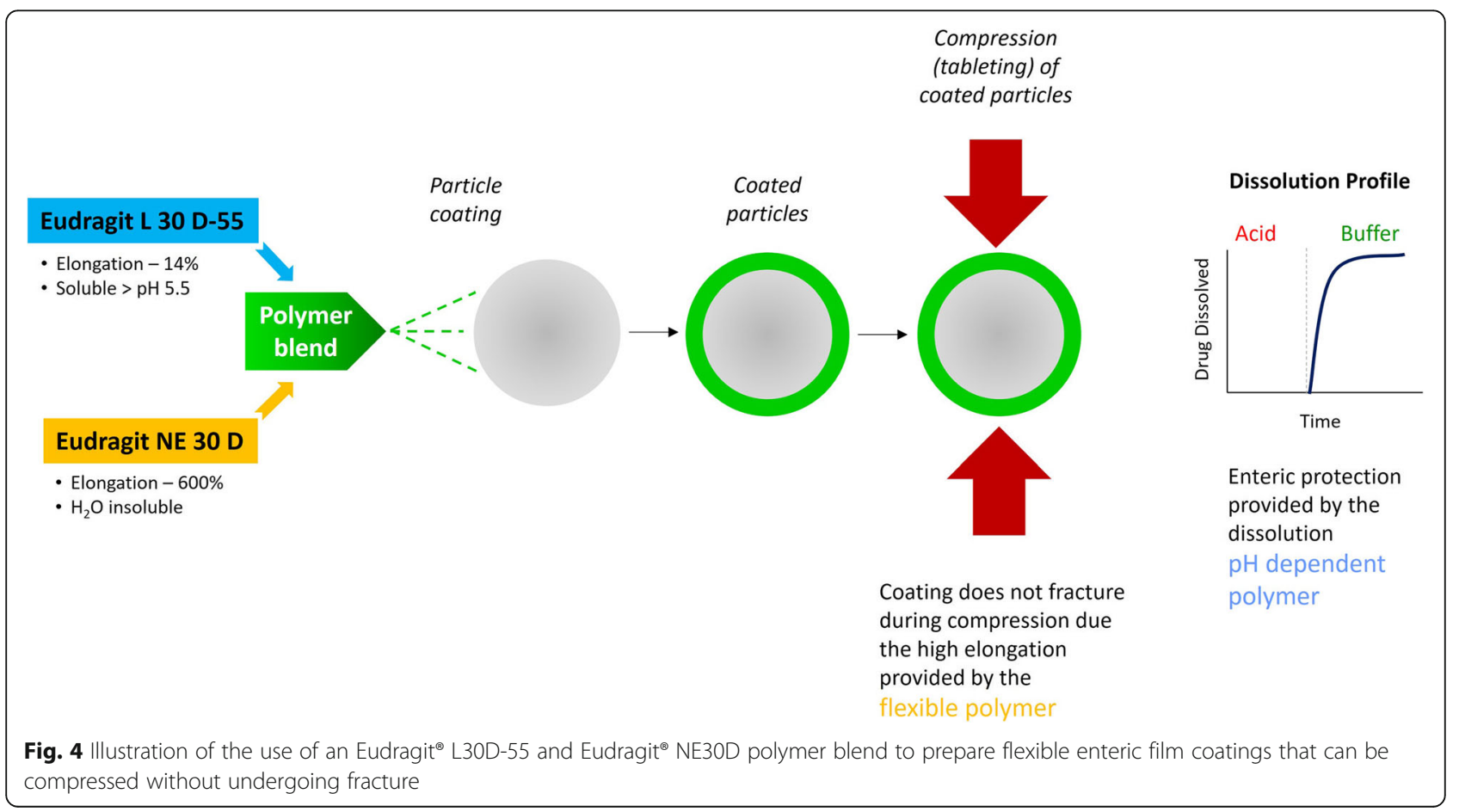


forming pores in the ethylcellulose coating which promote disintegration and drug release. An enteric coating based on an alginate and pectin blend has also been reported [102].

Oral thin films are used in lingual (for enteral), sublingual, and buccal drug delivery. Orodispersible films (ODFs) are a convenient dosage form for pediatrics and persons with dysphagia [103, 104]. Oral films are matrix systems with the polymers determining key factors such as drug loading, mechanical characteristics, handling, mucoadhesion, and disintegration times [103]. In a patented system which combines PEO and cellulosic polymers, controlling the polymer ratio is used as a means to modulate resistance to tearing, film flexibility, mucoadhesion, and drug release rates [23]. Furthermore, because of their inherent flexibility, polymers such as PEO and HPC can be used instead of low molecular weight plasticizers in oral films made by wet casting [24].

\section{Capsules}

For many years, gelatin was the sole option as the shell forming material for both hard and soft capsules. However, its animal origin, bovine spongiform encephalopathy/transmissible spongiform encephalopathy concerns, and its cross-linking potential have been major concerns which have led to the development of non-animal origin capsules. Many of these plant-based capsules use more than one polymer to form the capsule shell (Table 4).

First-generation hard (two-piece) HPMC capsules incorporate an additional polymer such as carrageenan or gellan gum [10, 105]. This additional polymer facilitates setting of the polymer solution and gelling, which is required for capsule manufacturing by a dip molding process. Interestingly, the amounts of the additional polymer required to facilitate gelling are very low, being in the range of $1 \%(\mathrm{w} / \mathrm{w})$ or less (based on the HPMC level) [106]. Second-generation HPMC capsules have now been developed which do not require a gelling agent instead inducing gelation by the use of heated molding pins (thermogelling process). Non-gelatin capsules are currently more expensive than gelatin capsules due to higher raw material and manufacturing costs; however, their lower sensitivity to environmental temperature and moisture should also be considered in an overall cost analysis $[107,108]$.

Another application of polymer blends has been in the development of non-coated enteric hard capsules. While capsules can be film coated with enteric polymers, this process adds an additional unit operation and level of complexity in drug product manufacturing. The development of capsules with an enteric functionality incorporated within the shell has therefore been a significant advancement in capsule technology. Another advantage of enteric capsules is that they can be used for very small batches that are prepared by filling individual capsules manually or with small scale capsule filling equipment which is extremely useful in early drug development and preclinical studies where there is a limited supply of the drug substance.

Two hard capsule products with $\mathrm{pH}$-dependent dissolution are currently marketed-DRcaps ${ }^{\circ}$ (for nutritional products and dietary supplements) and $\mathrm{Vcaps}^{\circ}$ enteric capsules. DRcaps ${ }^{\circ}$ are made of HPMC and gellan gum. Delayed release is obtained by the use of higher levels of gellan gum compared to those used in immediate release HPMC/gellan gum-based capsules [109]. Gellan gum is a heteropolysaccharide comprised of glucose, rhamnose and glucuronic acid units. Zeta potential measurements have shown that the ionization of gums which contain acidic groups decreases with $\mathrm{pH}$ [110], which explains the basis for the pH-dependent dissolution of capsules made with higher levels of gellan gum. Vcaps ${ }^{\circledR}$ enteric capsules, which are based on HPMC and hydroxypropyl methylcellulose acetate succinate (HPMC-AS), are an enteric product for pharmaceuticals, with the enteric

Table 4 Polymer blends used in capsules

\begin{tabular}{|c|c|c|c|}
\hline Polymers & Advantage(s) & Commercial product & Ref. \\
\hline HPMC, carrageenan & Plant based (gelatin free) & $\begin{array}{l}\text { Quali-V }{ }^{\circledR} \text { hard capsules } \\
\text { (Shionogi Qualicaps) }\end{array}$ & {$[10]$} \\
\hline HPMC, gellan gum & Plant based (gelatin free) & Vcaps $^{\circledast}$ hard capsules (Capsugel) & {$[10]$} \\
\hline HPMC, gellan gum & $\begin{array}{l}\text { - Enteric functionality (without the need for enteric coating) } \\
\text { - GRAS excipients } \\
\text { - Plant based (gelatin free) }\end{array}$ & $\begin{array}{l}\text { DRcaps }{ }^{\circledast} \text { hard capsules } \\
\text { (Capsugel) }\end{array}$ & {$[10]$} \\
\hline HPMC, HPMC-AS & $\begin{array}{l}\text { - Enteric functionality (without the need for enteric coating) } \\
\text { - Plant based (gelatin free) }\end{array}$ & $\begin{array}{l}\text { Vcaps }^{\circledast} \text { enteric hard capsules } \\
\text { (Capsugel) }\end{array}$ & {$[10]$} \\
\hline $\begin{array}{l}\text { Carrageenan, starch/modified } \\
\text { starch }\end{array}$ & Plant-based (gelatin free) soft capsules & $\begin{array}{l}\text { - Vegesoft vegetarian softgels } \\
\text { (Eurocaps) } \\
\text { - } \text { Versagel }^{\mathrm{TM}} \text { (Procaps) }\end{array}$ & $\begin{array}{l}{[11,} \\
12]\end{array}$ \\
\hline $\begin{array}{l}\text { Gelatin, methacrylic acid } \\
\text { copolymer type A }\end{array}$ & $\begin{array}{l}\text { Gelatin-based softgels with enteric functionality (avoids the need for } \\
\text { enteric coating) }\end{array}$ & Entericare $^{\mathrm{TM}}$ softgels (Patheon) & {$[13]$} \\
\hline
\end{tabular}

Abbreviations: GRAS generally regarded as safe, HPMC hypromellose, HPMC-AS hydroxypropyl methylcellulose acetate succinate 
function coming from the HPMC-AS polymeric component.

Soft capsules, which are more amenable to liquid, paste, and oil fills than hard capsules, have also become available in plant-based versions. Immediate release non-gelatin soft capsules made of modified starch and carrageen are commercially available [111].

Polymer blends have been used to develop inherently enteric soft shell capsules in which $\mathrm{pH}$-dependent dissolution is obtained by combining enteric polymers with gelatin [13, 112-114]. Enteric soft shell capsules using natural anionic GRAS polysaccharides, such as pectin, to provide enteric function have also been patented [115].

\section{Bioavailability enhancement and melt extrusion}

Polymer blends have been used to improve drug dissolution especially by techniques, such as hot melt extrusion (HME), which can be used to manufacture solid dispersions. The HME process provides thermal energy that melts or softens materials along with intense mixing, facilitating the dissolution or fine dispersion of drug substances in polymeric matrices. Under certain conditions, it is possible to produce amorphous or microcrystalline dispersions which exhibit improved drug dissolution. A balance of hydrophobicity and hydrophilicity in solid dispersions may be required to prevent crystallization and control drug dissolution and supersaturation [116]. These requirements may necessitate the use of more than one polymer. Synergistic effects on crystal growth inhibition of ritonavir have been reported for binary polymer blends [117]. Interestingly, combinations of a hydrophobic polymer (zein) and a hydrophilic polymer (HPMC) in spray dried isradipine solid dispersions were observed to reduce drug crystallinity and enhance drug dissolution more effectively than the individual polymers [118].

The Noxafil ${ }^{\circ}$ and Nucynta ${ }^{\circ}$ ER products listed in Table 5 are manufactured by melt extrusion [119, 120]. HME is listed as alternative manufacturing method for sublingual films which are commonly manufactured by wet casting techniques [23, 24].

Mixtures of low molecular weight polymers such as polyethylene glycols and poloxamers have been utilized in a marketed solid dispersion. In the patented Meltdose $^{\circ}$ technology, a combination of PEG 6000 and poloxamer 188 is used to dissolve tacrolimus and create a solid dispersion which is then sprayed onto a lactose carrier [21].

HME is also used to produce delivery devices such as implants and inserts. Lacrisert ${ }^{\circ}$, an ophthalmic insert made solely of hydroxypropyl cellulose and used to treat dry eye syndrome, was the first pharmaceutical melt extruded product [121]. An example of an implant which combines several polymers is Durysta ${ }^{\mathrm{TM}}$ (bimatoprost), a recently approved (2020) ophthalmic sustained release implant that is administered by intercameral injection. The product is used to reduce intraocular pressure in patients with open angle glaucoma or ocular hypertension. The implant is made from the biodegradable polymers poly(D,L-lactide) (PLA), poly(D,L-lactide-coglycolide) (PLGA), and poly (D,L-lactide) with an acid end group [30]. The Durysta ${ }^{\mathrm{TM}}$ implant is designed to release bimatoprost for 3-4 months, which is a significant advantage in reduction of dosing frequency compared to the daily use of eye drops [122]. The implant is manufactured by extruding a blend of the polymers and the active into filaments which are then cut to the dimensions of the implant [123]. In contrast to the previously mentioned HPMC-type polymers which are biologically inert in vivo, these polymers hydrolyze in vivo yielding natural carboxylic acids. The different biodegradable polymer chemistries are used to tailor the duration of drug release and the mechanical properties of the implant. PLA degrades more slowly as it is more hydrophobic than PLGA, while (carboxylic) acid endcapped polymers are more hydrophilic than their ester end-capped counterparts. The acid end groups also increase the rate of degradation by autocatalyzing hydrolysis of ester linkages in the polymer backbone [124].

\section{Commercial products and technology platforms}

Polymer blends have been used in several commercially marketed products, a number of which are listed in Table 5. For ease of reference, the polymeric blend components used in these products are listed separately from other excipients in the formulation. In general, the techniques in which the polymer blends are formed can be divided into three types: (1) powder-based blending, (2) melt/thermal blending, and (3) solvent-based liquid blending. In the case of solvent-based blending, the product may be further processed by drying to obtain a final product (e.g., oral films, capsule shells).

Several of the products listed in Table 5 have patented compositions and methods of manufacturing. A number of these patents are also part of proprietary technology platforms. For example, Acuform ${ }^{\circ}$ [125] BEMA ${ }^{\circ}$ (abbreviation for BioErodible MucoAdhesive) [126], NOVADUR [127], and Pharmfilm ${ }^{\circ}$ [25] are technology platforms used for the products Glumetza ${ }^{\circ}$, Belbuca ${ }^{\circ}$, Durysta $^{\mathrm{T} w}$, and Sympazan ${ }^{\circ}$, respectively.

In most of the examples listed, the polymer blends are formed during the manufacture of the dosage form with the exception of the $\mathrm{XHANCE}^{\circ}$ nasal spray product in which the polymer blend in the formulation derives from the use of a co-processed excipient (MCC/ $\mathrm{NaCMC}$ ). Various manufacturing techniques are used to incorporate the polymers including direct compression and HME for tablets. Casting from solution is used for 
Table 5 Polymer blends in selected marketed products

\begin{tabular}{|c|c|c|}
\hline $\begin{array}{l}\text { Commercial product/API/dosage form/ } \\
\text { manufacturing proccess }\end{array}$ & Polymeric/non-polymeric excipients (manufacturing process) & Company \\
\hline $\begin{array}{l}\text { lumetza } / \text { Metformin } \mathrm{HCl} \text { 500-mg/tablets/not dis- } \\
\text { losed (patent examples list direct compression) }\end{array}$ & $\begin{array}{l}\text { Hypromellose, microcrystalline cellulose, polyethylene oxide/coloring, } \\
\text { magnesium stearate }\end{array}$ & $\begin{array}{l}\text { Assertio } \\
\text { Therapeutics }\end{array}$ \\
\hline $\begin{array}{l}\text { oxafilø/posaconazole } 100 \text { mg/gastro-resistant tablets/ } \\
\text { ME }\end{array}$ & $\begin{array}{l}\text { Tablet core: hypromellose acetate succinate, cellulose microcrystalline, } \\
\text { hydroxypropylcellulose, croscarmellose sodium/silica dental type, }\end{array}$ & Mer \\
\hline
\end{tabular}

Film coating: polyvinyl alcohol, macrogol 3350/titanium dioxide, talc, iron oxide yellow

Isoptrin ${ }^{\circledast}$ SR/verapamil HCl 120, 180, 240-mg/sustainedrelease tablets/not disclosed tended-release tablets/HME

Envarsus XR $\mathrm{XR} /$ tacrolimus $0.75 \mathrm{mg}, 1 \mathrm{mg}, 4 \mathrm{mg} /$ extended-release tablets/melt drug-polymer solution coated onto carrier

Sympazan ${ }^{\circledast}$ oral film/clobazam/5, 10, 20 mg/orally dissolving film strips/wet casting (HME listed as an alternative)

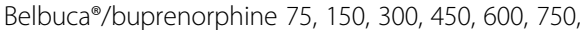

$900 \mathrm{mcg} / \mathrm{buccal}$ film/wet casting

Cod liver oil high strength/omega 3 fish oils/capsules/ liquid-gel mixing

Genteal ${ }^{\oplus}$ tears severe lubricant eye gel/HPMC/gel/ liquid mixing

Durysta $^{\mathrm{TM}} /$ bimatoprost $10 \mathrm{mcg} /$ biodegradable implant/HME

Sinuva ${ }^{\mathrm{TM}} / 1350$ mcg of mometasone furoate/sinus implant/drug-polymer coating of extrudate

XHANCE $\otimes / 93 \mathrm{mcg}$ of fluticasone propionate in each 106-mg spray/nasal spray/liquid mixing

Neupro ${ }^{\oplus}$ rotigotine $2 \mathrm{mg} /$ transdermal patch/film casting
Tablet core: alginate, microcrystalline cellulose polyvinyl pyrrolidone/magnesium stearate

Film coating: hypromellose, polyethylene glycol/talc, titanium dioxide, color additives

Tablet core: hypromellose, polyethylene glycol, polyethylene oxide/ alpha-tocopherol (vitamin E)

Film coating: polyvinyl alcohol, polyethylene glycol/talc, titanium dioxide, coloring agents and printing inks

Polyethylene glycol, poloxamer, hypromellose/lactose monohydrate, magnesium stearate, tartaric acid, butylated hydroxytoluene, and dimethicone

Hypromellose, polyethylene oxide/artificial cooling flavor, citric acid, glycerol monooleate, maltitol, natural and artificial bitter masker, natural raspberry type flavor, purified water, sodium phosphate dibasic, and sucralose

Mucoadhesive layer: carmellose sodium, hydroxyethyl cellulose, hydroxypropyl cellulose, polycarbophil/propylene glycol, sodium benzoate, methylparaben, propylparaben, iron oxide, anhydrous citric acid, vitamin E acetate, monobasic sodium phosphate (anhydrous), sodium hydroxide

Backing layer: hydroxypropyl cellulose and hydroxyethyl cellulose and non-polymeric components

Capsule shell: modified maize starch, carrageenan/glycerol, sodium carbonate

Hypromellose, carbopol 980/phosphoric acid, purified water, sodium hydroxide, sodium perborate, and sorbitol

Poly(D,L-lactide), poly (D,L-lactide-co-glycolide), poly (D,L-lactide) acid end, polyethylene glycol 3350

Poly(D,L-lactide-co-glycolide), polyethylene glycol

Microcrystalline cellulose, carboxymethylcellulose sodium/dextrose, benzalkonium chloride, polysorbate 80 , edetate disodium dihydrate, purified water

Self adhesive matrix layer: poly(dimethylsiloxane, trimethylsilyl silicate)copolymerisate, povidone K90/sodium metabisulphite, ascorbyl palmitate, DL-a-tocopherol (NB: product also has a backing layer and release liner)
Ranbaxy $\quad[17-$

Collegium

Pharmaceutical

Veloxis

$[21$,

Aquestive

$[23-$

Therapeutics

25]

BioDelivery

$[26$ Sciences

Seven Seas

Alcon

Allergan

Intersect ENT

OptiNose

UCB Pharma

$[33$, Limited 34]

Abbreviations: API active pharmaceutical ingredient, HME hot melt extrusion, HPMC hypromellose

the oral film and transdermal patch products. It is also possible to manufacture such products by melt extrusion provided the components have adequate thermal stability. The solution and suspension type liquid dosage forms incorporating polymer blends include an ophthalmic gel and the previously mentioned nasal spray, respectively. The large number of products prepared by HME indicates that this technique is particularly suited to polymer processing, especially in cases where fine or molecular dispersion of the API and excipients is required.
Polymer blends are often used in lubricating ophthalmic drops as a combination of polymers helps optimize the product requirements for lubrication, viscosity and ocular retention time. Examples of these blends include HPMC/Carbopol (Genteal ${ }^{\circ}$ tears, Table 5) and polyvinyl alcohol/povidone [128, 129].

A number of products listed in Table 5 use more than two polymers. Noxafil ${ }^{\circ}$ tablets and Belbuca ${ }^{\circ}$ buccal films, for example, both use four polymers. The individual polymers provide various functionalities. In Noxafil ${ }^{\circ}$ tablets, hypromellose acetate succinate, microcrystalline 
cellulose, hydroxypropyl cellulose, and croscarmellose sodium provide bioavailability enhancement, diluent/dry binding, dry binding/disintegrant, and disintegrant functionality, respectively. The contributions of the individual polymers used in Belbuca ${ }^{\circ}$ are not described in the relevant patent, but in general (with regard to oral films), carmellose sodium and polycarbophil have mucoadhesive properties while hydroxyethyl cellulose and hydroxypropyl cellulose are film formers.

\section{Conclusion}

The blending of polymers is a valuable approach in addressing limitations of individual polymers. The key advantages of using blends of approved polymers in drug delivery are twofold: (1) complementary polymer functionality or benefits can be achieved and (2) the resource-intensive, lengthy regulatory and safety evaluation process for a novel excipient is not required. The large number of currently existing polymers with established safety profiles and a history of use in pharmaceutical and biomedical products means that there are numerous polymer blend combinations that are possible, with the potential to address many of the formulation challenges encountered in the development of new drug products. Of critical importance to the rational selection and use of these polymer blends is the characterization and understanding of the nature of polymer-polymer interactions in these systems. This enables the design of novel polymer blends that can be manufactured in a consistent manner and address unmet needs in polymerbased drug delivery.

\section{Acknowledgements}

Not applicable.

\section{Author's contributions}

Not applicable (single author). The author read and approved the final manuscript.

\section{Funding}

Not applicable.

\section{Availability of data and materials}

Data and material are available upon request.

Ethics approval and consent to participate

Not applicable.

\section{Consent for publication}

Not applicable.

\section{Competing interests}

The author declares that there are no competing interests regarding this work.
Received: 5 October 2020 Accepted: 26 December 2020

Published online: 13 January 2021

\section{References}

1. Imre B, Pukánszky B (2013) Compatibilization in bio-based and biodegradable polymer blends. Eur Polym J 49:1215-1233. https://doi.org/ 10.1016/j.eurpolymj.2013.01.019

2. Gusler G, Berner B, Chau M, Padua A (2004) Optimal polymer mixtures for gastric retentive tablets, US Patent 6,723,340B2, 2004

3. Staniforth JN, Baichwal AR (2005) TIMERx: novel polysaccharide composites for controlled/programmed release of drugs in the gastrointestinal tract. Expert Opin Drug Deliv 2:587-595. https://doi.org/10.1517/17425247.2.3.587

4. McGinley EJ, Tuason DC (1993) Fat-like bulking agent for aqueous foods comprising microcrystalline cellulose and a galactomannan gum, US Patent 5,192,569A, 1993

5. Koo OM, Fiske JD, Yang H, Nikfar F, Thakur A, Scheer B, Adams ML (2011) Investigation into stability of poly(vinyl alcohol)-based Opadry ${ }^{\circledast}$ || films. AAPS PharmSciTech 12:746-754. https://doi.org/10.1208/s12249-011-9630-1

6. Kerry (2015) Sheffcoat ${ }^{\text {TM }}$ Aqueous Based Coating Systems brochure. https:// www.kerry.com/-/media/documents/pdfs/sheffcoat-brochure-aug2015. ashx?la=en-gb. Accessed 25 Sept 2020.

7. Müller-Albers J, Guha A, Assmus M (2018) Use of an advanced new enteric combination polymer with multiple unit pellet systems and other multiparticulates. Am Pharm Rev

8. Skalsky B, Petereit HU (2008) Chemistry and application properties of polymethacrylate systems. In: McGinity JW, Felton LA (eds) Aqueous Polymeric Coatings for Pharmaceutical Dosage Forms, 3rd edn. Informa Healthcare, New York, pp 237-277

9. Young C, Dietzsch C, Fegely K, Rajabi-Siahboomi A (2006) The influence of a $\mathrm{pH}$ dependent pore former on acid protection from tablets coated with an aqueous ethylcellulose barrier membrane. https://www.colorcon.com/ item/1988-crs-2010-the-influence-of-a-ph-dependent-pore-former-on-acidprotection-from-tablets-coated-with-an-aqueous-ethylcellulose-barriermembrane. Accessed 25 Sept 2020.

10. Gullapalli RP, Mazzitelli CL (2017) Gelatin and non-gelatin capsule dosage forms. J Pharm Sci 106:1453-1465. https://doi.org/10.1016/j.xphs.2017.02.006

11. Eurocaps (2020) Vegesoft Vegetarian Softgels. https://www.eurocaps.co.uk/ products/vegesoft-vegetarian-softgels/. Accessed 25 Sept 2020.

12. Procaps (2018) Non-animal gelatin soft capsules - VersagelTM. http://web. softigel.com/softgel-technologies/versagel\%E2\%84\%A2. Accessed 25 Sept 2020.

13. Vaughn JM, Hughey JR, Roberts T, Dyakonov T, Agnihotri S, Fatmi AA (2018) Fumarate ester dosage forms, US Patent 10,105,335B2, 2018

14. Depomed (2009) Glumetza ${ }^{\oplus}$ metformin hydrochloride tablet, film coated, extended release product label.

15. Fang LY, Harris D, Krishna G, Moton AE, Prestipino RC, Steinman M, Wan J, Waskin HA (2009) High density compositions containing posaconazole and formulations comprising the same, Patent WO 2009129300A2, 2009

16. Merck (2019) Noxafil 100 mg Gastro-resistant Tablets summary of product characteristics. https://www.medicines.org.uk/emc/product/5388/. Accessed 25 Sep 2020.

17. Roth W, Setnik B, Zietsch M, Burst A, Breitenbach J, Sellers E, Brennan D (2009) Ethanol effects on drug release from Verapamil Meltrex, an innovative melt extruded formulation. Int J Pharm 368:72-75. https://doi. org/10.1016/j.jpharm.2008.09.052

18. Vajna B, Pataki H, Nagy Z, Farkas I, Marosi G (2011) Characterization of melt extruded and conventional Isoptin formulations using Raman chemical imaging and chemometrics. Int J Pharm 419:107-113. https://doi.org/10. 1016/j.jpharm.2011.07.023

19. Ranbaxy (2011) Isoptin ${ }^{\circledast}$ SR (verapamil HCl) sustained-release oral tablets product label.

20. Collegium (2019) NUCYNTA ${ }^{\oplus}$ ER product label.

21. Holm P, Norling T (2013) Modified release compositions comprising tacrolimus, US Patent 8,617,599B2, 2013

22. Veloxis (2019) Envarsus $X R^{\oplus}$ product label.

23. Yang RK, Fuisz RC, Myers GL, Fuisz JM (2013) Uniform films for rapid dissolve dosage form incorporating taste-masking compositions, US Patent 8,603,514B2, 2013

24. Yang RK, Fuisz RC, Myers GL, Fuisz JM (2018) Uniform films for rapid dissolve dosage form incorporating taste-masking compositions, US Patent 9,931,305B2, 2018 
25. Aquestive Therapeutics (2020) PharmFilm. https://aquestive.com/innovativedrug-delivery-pharmfilm/. Accessed 25 Sept 2020.

26. BioDelivery Sciences (2019) Belbuca ${ }^{\circledast}$ (buprenorphine buccal film) product label.

27. Finn A, Vasisht $N$ (2018) Transmucosal drug delivery devices for use in chronic pain relief, US Patent 9,901,539B2, 2018

28. Seven Seas (2018) Cod liver oil high strength capsules. https://www.sevenseas.com/en_GB/home/product-finder/cod-liver-oil-high-strength-capsules. html. Accessed 25 Sept 2020.

29. Alcon (2017) Genteal ${ }^{\circledR}$ tears severe lubricant eye gel product information. https://gentealtears.myalcon.com/eye-care/genteal/products/genteal-severe/ safety-information/. Accessed 25 Sept 2020

30. Allergan (2020) DurystaTM (bimatoprost implant) for intracameral administration product label.

31. Interseect ENT (2017) SINUVA ${ }^{\text {TM }}$ (mometasone furoate) sinus implant product label.

32. OptiNose (2019) XHANCE® (fluticasone propionate) nasal spray product label.

33. Wolff H, Arth C, Quere L, W M (2018) Polyvinylpyrrolidone for the stabilization of a solid dispersion of the non-crystalline form of rotigotine, US Patent 9,925,150B2, 2018.

34. UCB Pharma (2020) Neupro $2 \mathrm{mg} / 24 \mathrm{~h}$ Transdermal patch summary of product characteristics. https://www.medicines.org.uk/emc/product/186/ smpc. Accessed 25 Sept 2020.

35. Sakellariou P, Rowe RC, White EFT (1986) Polymer/polymer interaction in blends of ethyl cellulose with both cellulose derivatives and polyethylene glycol 6000. Int J Pharm 34:93-103. https://doi.org/10.1016/03785173(86)90014-1

36. Nyamweya N, Hoag SW (2000) Assessment of polymer-polymer interactions in blends of HPMC and film forming polymers by modulated temperature differential scanning calorimetry. Pharm Res 17:625-631. https://doi.org/10. 1023/A:1007585403781

37. Lecomte F, Siepmann J, Walther M, MacRae RJ, Bodmeier R (2003) Blends of enteric and GIT-insoluble polymers used for film coating: physicochemical characterization and drug release patterns. J Control Release 89:457-471. https://doi.org/10.1016/s0168-3659(03)00155-x

38. Chan LW, Ong KT, Heng PW (2005) Novel film modifiers to alter the physical properties of composite ethylcellulose films. Pharm Res 22:476-489. https:// doi.org/10.1007/s1 1095-004-1886-7

39. Tedesco MP, Monaco-Lourenço CA, Carvalho RA (2016) Gelatin/ hydroxypropyl methylcellulose matrices - polymer interactions approach for oral disintegrating films. Mater Sci Eng C 69:668-674. https://doi.org/10. 1016/j.msec.2016.07.023

40. Ranga Rao KV, Padmalatha Devi K, Buri P (1988) Cellulose matrices for zeroorder release of soluble drugs. Drug Dev Ind Pharm 14:2299-2320. https:// doi.org/10.3109/03639048809152017

41. Samani SM, Montaseri H, Kazemi A (2003) The effect of polymer blends on release profiles of diclofenac sodium from matrices. Eur J Pharm Biopharm 55:351-355. https://doi.org/10.1016/s0939-6411(03)00030-4

42. Ebube NK, Jones $A B$ (2004) Sustained release of acetaminophen from a heterogeneous mixture of two hydrophilic non-ionic cellulose ether polymers. Int J Pharm 272:19-27. https://doi.org/10.1016/j.jpharm.2003.11. 020

43. Papageorgiou GZ, Bikiaris D, Kanaze FI, Karavas E, Stergiou A, Georgarakis E (2008) Tailoring the release rates of fluconazole using solid dispersions in polymer blends. Drug Dev Ind Pharm 34:336-346. https://doi.org/10.1080/ 03639040701662669

44. Lehmkemper K, Kyeremateng SO, Bartels M, Degenhardt M, Sadowski G (2018) Physical stability of API/polymer-blend amorphous solid dispersions Eur J Pharm Biopharm 124:147-157. https://doi.org/10.1016/j.ejpb.2017.12. 002

45. Ueda K, Yamazoe C, Yasuda Y, Higashi K, Kawakami K, Moribe K (2018) Mechanism of enhanced nifedipine dissolution by polymer-blended solid dispersion through molecular-level characterization. Mol Pharm 15:40994109. https://doi.org/10.1021/acs.molpharmaceut.8b00523

46. Lao LL, Venkatraman SS, Peppas NA (2008) Modeling of drug release from biodegradable polymer blends. Eur J Pharm Biopharm 70:796-803. https:// doi.org/10.1016/j.ejpb.2008.05.024

47. Saini P, Arora M, Kumar M (2016) Poly(lactic acid) blends in biomedical applications. Adv Drug Deliv Rev 107:47-59. https://doi.org/10.1016/j.addr. 2016.06.014
48. Pichayakorn W, Suksaeree J, Boonme P, Amnuaikit T, Taweepreda W, Ritthidej G (2012) Nicotine transdermal patches using polymeric natural rubber as the matrix controlling system: Effect of polymer and plasticizer blends. J Membr Sci 411-412:81-90. https://doi.org/10.1016/j.memsci.2012. 04.017

49. Bajpai AK, Shukla SK, Bhanu S, Kankane S (2008) Responsive polymers in controlled drug delivery. Prog Polym Sci 33:1088-1118. https://doi.org/10. 1016/j.progpolymsci.2008.07.005

50. De Souza Ferreira SB, Moço TD, Borghi-Pangoni FB, Junqueira MV, Bruschi ML (2016) Rheological, mucoadhesive and textural properties of thermoresponsive polymer blends for biomedical applications. J Mech Behav Biomed Mater 55:164-178. https://doi.org/10.1016/j.jmbbm.2015.10. 026

51. Cascone MG, Sim B, Sandra D (1995) Blends of synthetic and natural polymers as drug delivery systems for growth hormone. Biomaterials 16 : 569-574. https://doi.org/10.1016/0142-9612(95)91131-H

52. Yu L, Dean K, Li L (2006) Polymer blends and composites from renewable resources. Prog Polym Sci 31:576-602. https://doi.org/10.1016/j. progpolymsci.2006.03.002

53. Laurienzo P (2010) Marine polysaccharides in pharmaceutical applications: an overview. Mar Drugs 8:2435-2465. https://doi.org/10.3390/md8092435

54. Szymańska E, Winnicka K (2015) Stability of chitosan-a challenge for pharmaceutical and biomedical applications. Mar Drugs 13:1819-1846. https://doi.org/10.3390/md13041819

55. Maghsoudi S, Taghavi Shahraki B, Rabiee N, Fatahi Y, Dinarvand R, Tavakolizadeh M, Ahmadi S, Rabiee M, Bagherzadeh M, Pourjavadi A, Farhadnejad H, Tahriri M, Webster TJ, Tayebi L (2020) Burgeoning polymer nano blends for improved controlled drug release: a review. Int J Nanomedicine 15:4363-4392. https://doi.org/10.2147/IJN.S252237

56. Alhijjaj M, Belton P, Qi S (2016) An investigation into the use of polymer blends to improve the printability of and regulate drug release from pharmaceutical solid dispersions prepared via fused deposition modeling (FDM) 3D printing. Eur J Pharm Biopharm 108:111-125. https://doi.org/10. 1016/j.ejpb.2016.08.016

57. Khaled SA, Burley JC, Alexander MR, Roberts CJ (2014) Desktop 3D printing of controlled release pharmaceutical bilayer tablets. Int J Pharm 461:105111. https://doi.org/10.1016/j.ijpharm.2013.11.021

58. Solanki NG, Tahsin M, Shah AV, Serajuddin A (2018) Formulation of 3D printed tablet for rapid drug release by fused deposition modeling: screening polymers for drug release, drug-polymer miscibility and printability. J Pharm Sci 107:390-401. https://doi.org/10.1016/j.xphs.2017.10. 021

59. Carson D, Jiang Y, Woodrow KA (2016) Tunable release of multiclass antiHIV drugs that are water-soluble and loaded at high drug content in polyester blended electrospun fibers. Pharm Res 33:125-136. https://doi.org/ 10.1007/s11095-015-1769-0

60. Chachlioutaki K, Tzimtzimis EK, Tzetzis D, Chang MW, Ahmad Z, Karavasili C, Fatouros DG (2020) Electrospun orodispersible films of isoniazid for pediatric tuberculosis treatment. Pharmaceutics 12:470. https://doi.org/10.3390/ pharmaceutics 12050470

61. Qin ZY, Jia XW, Liu Q, Kong BH, Wang H (2019) Fast dissolving oral films for drug delivery prepared from chitosan/pullulan electrospinning nanofibers. Int J Biol Macromol 137:224-231. https://doi.org/10.1016/jijbiomac.2019.06. 224

62. Sill TJ, von Recum HA (2008) Electrospinning: applications in drug delivery and tissue engineering. Biomaterials 29:1989-2006. https://doi.org/10.1016/j. biomaterials.2008.01.011

63. Hu X, Liu S, Zhou G, Huang Y, Xie Z, Jing X (2014) Electrospinning of polymeric nanofibers for drug delivery applications. J Control Release 185: 12-21. https://doi.org/10.1016/j.jconrel.2014.04.018

64. Abdelrazek EM, Elashmawi IS, Labeeb S (2010) Chitosan filler effects on the experimental characterization, spectroscopic investigation and thermal studies of PVA/PVP blend films. Physica B: Condens Matter 405:2021-2027. https://doi.org/10.1016/.jphysb.2010.01.095

65. Parameswaranpillai J, Thomas S, Grohens Y (2015) In: Thomas S, Grohens Y, Jyotishkumar P (eds) Polymer blends: state of the art, new challenges, and opportunities. Wiley-VCH Verlag GmbH \& Co. KGaA, Weinheim, pp 1-6

66. Mi FL, Shyu SS, Lin YM, Wu YB, Peng CK, Tsai YH (2003) Chitin/PLGA blend microspheres as a biodegradable drug delivery system: a new delivery system for protein. Biomaterials 24:5023-5036. https://doi.org/10.1016/ s0142-9612(03)00413-7 
67. Gupta B, Agarwal R, Sarwar Alam M (2012) Preparation and characterization of polyvinyl alcohol-polyethylene oxide-carboxymethyl cellulose blend membranes. J Appl Polym Sci 127:1301-1308. https://doi.org/10.1002/app 37665

68. Yang Z, Nollenberger K, Albers J, Craig D, Qi S (2013) Microstructure of an immiscible polymer blend and its stabilization effect on amorphous solid dispersions. Mol Pharm 10:2767-2780. https://doi.org/10.1021/ mp400209w

69. Abu Fara D, Dadou SM, Rashid I, Al-Obeidi R, Antonijevic MD, Chowdhry BZ, Badwan A (2019) A direct compression matrix made from xanthan gum and low molecular weight chitosan designed to improve compressibility in controlled release tablets. Pharmaceutics 11:603. https://doi.org/10.3390/ pharmaceutics 11110603

70. Cagel M, Tesan FC, Bernabeu E, Salgueiro MJ, Zubillaga MB, Moretton MA, Chiappetta DA (2017) Polymeric mixed micelles as nanomedicines: Achievements and perspectives. Eur J Pharm Biopharm 113:211-228. https://doi.org/10.1016/j.ejpb.2016.12.019

71. Dashevsky A, Ahmed AR, Mota J, Irfan M, Kolter K, Bodmeier RA (2010) Effect of water-soluble polymers on the physical stability of aqueous polymeric dispersions and their implications on the drug release from coated pellets. Drug Dev Ind Pharm 36:152-160. https://doi.org/10.3109/ 03639040903410334

72. Seebergh JE, Berg JC (1994) Depletion flocculation of aqueous, electrosterically-stabilized latex dispersions. Langmuir 10:454-463. https:// doi.org/10.1021/la00014a020

73. Bruce LD, McGinity JW (2008) Polymer interactions with drugs and excipients. In: McGinity JW, Felton LA (eds) Aqueous Polymeric Coatings for Pharmaceutical Dosage Forms, 3rd edn. Informa Healthcare, New York, pp 369-408

74. Durand HW, E.G. F, Raynor GE (1970) Dispersing and stabilizing agent comprising beta-1,4 glucan and CMC and method for its preparation. US Patent 3,539,365A, 1970.

75. Walkling WD, Shangraw RF (1968) Rheology of microcrystalline cellulosecarboxymethylcellulose gels. J Pharm Sci 57:1927-1933. https://doi.org/10. 1002/jps.2600571121

76. Zhao GH, Kapur N, Carlin B, Selinger E, Guthrie JT (2011) Characterisation of the interactive properties of microcrystalline cellulose-carboxymethyl cellulose hydrogels. Int J Pharm 415:95-101. https://doi.org/10.1016/j. ijpharm.2011.05.054

77. Quinn ME, Rowe RC (2009) Cellulose, microcrystalline and carboxymethylcellulose sodium. In: Rowe RC, Sheskey PJ, Quinn ME (eds) Handbook of Pharmaceutical Excipients, 6th edn. American Pharmaceutical Association and the Pharmaceutical Press, Washington DC, London, pp $134-135$

78. GSK (2020) Avamys 27.5 micrograms/spray, nasal spray suspension summary of product characteristics. https://www.medicines.org.uk/emc/product/6439/ smpc. Accessed 25 Sept 2020.

79. GSK (2019) Beconase Aqueous Nasal Spray summary of product characteristics. https://www.medicines.org.uk/emc/product/844/smpc. Accessed 25 Sept 2020.

80. Sanofi (2018) Nasacort Allergy 55 micrograms/dose Nasal Spray suspension summary of product characteristics. https://www.medicines.org.uk/emc/ product/6501/smpc. Accessed 25 Sept 2020.

81. Tuason DC, G.R. K, Buliga G (2010) Microcrystalline cellulose. In: Imeson A (ed) Food stabilisers, thickeners, and gelling agents. Wiley, Chichester, pp 218-236

82. Lawless HT, Tuorila H, Jouppila K, Virtanen P, Horne J (2007) Effects of guar gum and microcrystalline cellulose on sensory and thermal properties of a high fat model food system. J Texture Stud 27:493-516. https://doi.org/10. 1111/j.1745-4603.1996.tb00091.x

83. Ratnaraj S, Reilly WJ (1997) Chewable pharmaceutical tablets, US Patent $5,686,107 \mathrm{~A}, 1997$

84. Saha S, Shahiwala AF (2009) Multifunctional coprocessed excipients for improved tabletting performance. Expert Opin Drug Deliv 6:197-208. https://doi.org/10.1517/17425240802708978

85. Li CL, Martini LG, Ford JL, Roberts M (2005) The use of hypromellose in oral drug delivery. J Pharm Pharmacol 57:533-546. https://doi.org/10.1211/ 0022357055957

86. Tiwari SB, Rajabi-Siahboomi AR (2009) Applications of complementary polymers in HPMC hydrophilic extended release matrices. Drug Deliv Technol 9:20-27
87. Streubel A, Siepmann J, Dashevsky A, Bodmeier R (2000) pH-independent release of a weakly basic drug from water-insoluble and -soluble matrix tablets. J Control Release 67:101-110. https://doi.org/10.1016/s01683659(00)00200-5

88. Tatavarti AS, Mehta KA, Augsburger LL, Hoag SW (2004) Influence of methacrylic and acrylic acid polymers on the release performance of weakly basic drugs from sustained release hydrophilic matrices. J Pharm Sci 93: 2319-2331. https://doi.org/10.1002/jps.20129

89. Timmins P, Delargy AM, Howard JR (1997) Optimization and characterization of a $\mathrm{pH}$-independent extended-release hydrophilic matrix tablet. Pharm Dev Technol 2:25-31. https://doi.org/10.3109/ 10837459709022606

90. Rao VM, Engh K, Qiu Y (2003) Design of pH-independent controlled release matrix tablets for acidic drugs. Int J Pharm 252:81-86. https://doi.org/10. 1016/s0378-5173(02)00622-1

91. Walker CV, Wells JI (1982) Rheological synergism between ionic and nonionic cellulose gums. Int J Pharm 11:309-322. https://doi.org/10.1016/03785173(82)90081-3

92. Rao KVR, Devi KP, Buri P (1990) Influence of molecular size and water solubility of the solute on its release from swelling and erosion controlled polymeric matrices. J Control Release 12:133-141. https://doi.org/10.1016/ 0168-3659(90)90089-C

93. Dabbagh MA, Ford JL, Rubinstein MH, Hogan JE, Rajabi-Siahboomi AR (1999) Release of propranolol hydrochloride from matrix tablets containing sodium carboxymethylcellulose and hydroxypropylmethylcellulose. Pharm Dev Technol 4:313-324. https://doi.org/10.1081/PDT-100101367

94. Omidian H, Park K (2010) Oral targeted drug delivery systems: gastric retention devices. In: Wen H, Park K (eds) Oral Controlled Release Formulation Design and Drug Delivery: Theory to Practice. Wiley, Hoboken, pp 185-204

95. FDA (2020) Inactive ingredient search for approved drug products. https:// www.accessdata.fda.gov/scripts/cder/iig/index.cfm. Accessed 25 Sept 2020.

96. Guo J, Skinner GW, Harcum WW, Barnum PE (1998) Pharmaceutical applications of naturally occurring water-soluble polymers. Pharm Sci Technol Today 1:254-261. https://doi.org/10.1016/S1461-5347(98)00072-8

97. Siepmann F, Siepmann J, Walther M, MacRae RJ, Bodmeier R (2008) Polymer blends for controlled release coatings. J Control Release 125:1-15. https:// doi.org/10.1016/j.jconrel.2007.09.012

98. Cole G, Hogan J, Aulton M (1995) Pharmaceutical coating technology. Taylor \& Francis Books, London

99. Nyamweya N, Hoag SW, Mehta KA (2001) Film coating with aqueous latex dispersions: general considerations for formulating with pigments. Pharm Technol pp 8-26

100. Zheng W, Sauer D, McGinity JW (2005) Influence of hydroxyethylcellulose on the drug release properties of theophylline pellets coated with Eudragit RS 30 D. Eur J Pharm Biopharm 59:147-154. https://doi.org/10.1016/j.ejpb. 2004.06.002

101. Czarnocka JK, Alhnan MA (2015) Gastro-resistant characteristics of GRASgrade enteric coatings for pharmaceutical and nutraceutical products. Int J Pharm 486:167-174. https://doi.org/10.1016/j.ijpharm.2015.03.039

102. Khoder M, Schropp V, Zeitler S, Pereira B, Habashy R, Royall PG, Wang JT, Alhnan MA (2020) A novel natural GRAS-grade enteric coating for pharmaceutical and nutraceutical products. Int J Pharm 584:119392. https:// doi.org/10.1016/j.ijpharm.2020.119392

103. Borges AF, Silva C, Coelho JF, Simões S (2015) Oral films: current status and future perspectives: I - Galenical development and quality attributes. J Control Release 206:1-19. https://doi.org/10.1016/j.jconrel.2015.03.006

104. Scarpa M, Stegemann S, Hsiao WK, Pichler H, Gaisford S, Bresciani M, Paudel A, Orlu M (2017) Orodispersible films: towards drug delivery in special populations. Int J Pharm 523:327-335. https://doi.org/10.1016/j.ijpharm.2017. 03.018

105. Al-Tabakha M (2010) HPMC capsules: current status and future prospects. J Pharm Pharm 13:428-442. https://doi.org/10.18433/j3k881

106. Cade D, Scott R, He X (2003) Polymer film compositions for capsules, US Patent 6,517,865B2, 2003

107. Prakash A, Soni H, Mishra A, Sarma P (2017) Are your capsules vegetarian or nonvegetarian: An ethical and scientific justification. Indian J Pharmacol 49: 401c404. https://doi.org/10.4103/ijp.IJP_409_17

108. Seufert K, Vatsa K (2016) HPMC capsules gain credibility as alternative to gelatin. Tablets Capsules 14:41-45

109. Cade DN, He XD (2014) Acid resistant capsules, US Patent 8,852,631B2, 2014 
110. Barbosa J, Abdelsadig M, Conway BR, Merchant HA (2019) Using zeta potential to study the ionisation behaviour of polymers employed in modified-release dosage forms and estimating their pKa. Int J Pharm X 1: 100024. https://doi.org/10.1016/j.jpx.2019.100024

111. Silva C, Vasta K (2020) Vegetarian substitutes for gelatin soft capsules. Tablets Capsules 18:18-22

112. Smith AM, Ingham A, Grover LM, Perrie Y (2010) Polymer film formulations for the preparation of enteric pharmaceutical capsules. J Pharm Pharmacol 62:167-172. https://doi.org/10.1211/jpp.62.02.0003

113. Hassan EM, Fatmi AA, Chidambaram N (2014) Enteric composition for the manufacture of soft capsule wall, US Patent 8,685,445B2, 2014

114. Hassan EM, Fatmi AA, Chidambaram N (2016) Enteric soft capsules, US Patent 9,433,585B2, 2016

115. Hu Y, Piest M, Fang Q, Van Duijnhoven MGMH (2019) All-natural enteric soft capsules, US Patent 10,357,467B2, 2019

116. Marks JA, Wegiel LA, Taylor LS, Edgar KJ (2014) Pairwise polymer blends for oral drug delivery. J Pharm Sci 103:2871-2883. https://doi.org/10.1002/jps.23991

117. Ilevbare GA, Liu H, Edgar KJ, Taylor LS (2012) Effect of binary additive combinations on solution crystal growth of the poorly water-soluble drug, ritonavir. Cryst Growth Des 12:6050-6060. https://doi.org/10.1021/cg301169t

118. Van Ngo H, Nguyen PK, Van Vo T, Duan W, Tran VT, Tran PH, Tran TT (2016) Hydrophilic-hydrophobic polymer blend for modulation of crystalline changes and molecular interactions in solid dispersion. Int J Pharm 513: 148-152. https://doi.org/10.1016/j.ijpharm.2016.09.017

119. Simões MF, Pinto R, Simões S (2019) Hot-melt extrusion in the pharmaceutical industry: toward filing a new drug application. Drug Discov Today 24:1749-1768. https://doi.org/10.1016/j.drudis.2019.05.013

120. Matić J, Paudel A, Bauer H, Garcia R, Biedrzycka K, Khinast JG (2020) Developing HME-based drug products using emerging science: a fast-track roadmap from concept to clinical batch. AAPS PharmSciTech 21:176. https://doi.org/10.1208/s12249-020-01713-0

121. Repka M, Langley N, DiNunzio J (2013) Melt extrusion: materials, technology and drug product design. Springer, New York, NY

122. Medeiros FA, Walters TR, Kolko M, Coote M, Bejanian M, Goodkin ML, Guo Q, Zhang J, Robinson MR, Weinreb RN, ARTEMIS 1 Study Group (2020) Phase 3, randomized, 20-month study of bimatoprost implant in openangle glaucoma and ocular hypertension (ARTEMIS 1). Ophthalmology. https://doi.org/10.1016/j.ophtha.2020.06.018

123. Ghebremeskel AN, Robinson MR (2016) Prostamide-containing intraocular implants and methods of use thereof, US Patent 9,492,316B2, 2016

124. Makadia HK, Siegel SJ (2011) Poly lactic-co-glycolic acid (PLGA) as biodegradable controlled drug delivery carrier. Polymers 3:1377-1397. https://doi.org/10.3390/polym3031377

125. Assertio Therapeutics (2020). https://www.assertiotx.com/products-andpipeline/technology/. Accessed 25 Sept 2020.

126. BioDelivery Sciences (2020) Products, Technology. https://bdsi.com/ technology. Accessed 25 Sept 2020.

127. Seal JR, Robinson MR, Burke J, Bejanian M, Coote M, Attar M (2019) Intracameral sustained-release bimatoprost implant delivers bimatoprost to target tissues with reduced drug exposure to off-target tissues. J Ocul Pharmacol Ther 35:50-57. https://doi.org/10.1089/jop.2018.0067

128. Calonge M (2001) The treatment of dry eye. Surv Ophthalmol 45:S227-S239. https://doi.org/10.1016/S0039-6257(00)00205-8

129. Tong L, Petznick A, Lee S, Tan J (2012) Choice of artificial tear formulation for patients with dry eye: where do we start? Cornea 31:S32-S36. https:// doi.org/10.1097/ICO.0b013e318269cb99

\section{Publisher's Note}

Springer Nature remains neutral with regard to jurisdictional claims in published maps and institutional affiliations.

\section{Submit your manuscript to a SpringerOpen ${ }^{\circ}$ journal and benefit from:}

- Convenient online submission

- Rigorous peer review

- Open access: articles freely available online

- High visibility within the field

- Retaining the copyright to your article

Submit your next manuscript at $\boldsymbol{\nabla}$ springeropen.com 